\title{
Spatial Distribution of Congenital Disorders Diagnosed by the Newborn Screening Program in Ecuador
}

Journal of Inborn Errors of Metabolism \& Screening 2021, Volume 9: e20200016 DOI: https://doi.org/10.1590/2326-4594 JIEMS-2020-0016

\author{
Juan Pozo-Palacios ${ }^{1,2,3 *}$ (D), Génesis García-Díaz', Fernando Cruz', \\ Fabián Porras ${ }^{1}$, Jessica Heras ${ }^{3}$ and Eder Cano-Pérez ${ }^{4,5}$
}

\begin{abstract}
The newborn screening program in Ecuador has been operating since 2011 under the responsibility of the Ministry of Health. This program is centralized and diagnoses four diseases: congenital hypothyroidism, phenylketonuria, galactosemia, and congenital adrenal hyperplasia. This study aimed to assess the geographical distribution of newborn screening cases in Ecuador. Spatial analysis techniques were applied using the records of the National Newborn Screening Program with a congenital disease confirmed from January 2012 to December 2019. Morbidity rates per 100,000 were calculated by newborn screening disease detected and the province of birth, posteriorly, the map of its distribution was graphed and assessed using the QGIS 3.12 software. In total, 393 cases born confirmed between 2012 and 2019 were registered. The distribution of every disease tends to be different in all provinces in Ecuador; the spatial variation was significant and relative rates showed a higher incidence in some eastern provinces. In conclusion, we found a different distribution and rates of newborn screening disorders in Ecuador. The high incidence of congenital hypothyroidism, phenylketonuria, galactosemia, and congenital adrenal hyperplasia in some areas should be investigated, due could be related to ethnic, genetic, and cultural aspects of the population.
\end{abstract}

Keywords: spatial distribution, newborn screening, congenital disorders, Ecuador.

\section{Introduction}

The newborn screening (NBS) is a preventive health program for early identification of disorders that can hinder their normal development or cause premature death [1]. The aim of the NBS program is early detection of congenital disorders in newborns and start a treatment to prevent intellectual and physical disabilities and life-threatening complications [2]. The NBS has been in place for many years in each country; the number of diseases tested varies in every country and its health program. Also, there is no international standard of the disorders that be tested [3]. In Latin America, countries such as Cuba, Costa Rica, Uruguay, and Chile have a functional screening program for more than 20 years. In others, like Ecuador, the screening program has been working for a few years [4].

The Ecuadorian Ministry of Public Health (MPH), the government body in charge of public health matters, functions on national and local levels and is responsible for the NBS program. This program started in Ecuador in December 2011 with the diagnosis of four diseases: congenital hypothyroidism, phenylketonuria, galactosemia, and congenital adrenal hyperplasia [5]. Before 2011, the only screening disorder detected in Ecuador was congenital hypothyroidism; however, this disorder was diagnosed in just a few local hospitals, and there was not a national screening program [6]. In 2009 and 2010, the country conducted a national study on disabilities. This study revealed that there were 68687 people with intellectual disabilities in Ecuador and described congenital hypothyroidism as an important cause of disabilities [7]. On the other hand, the rates of phenylketonuria, galactosemia, and congenital adrenal

\footnotetext{
'Ministerio de Salud Pública, Centro Especializado en Genética Médica (CEGEMED), Quito, Ecuador.

${ }^{2}$ Universidad de Cuenca, Facultad de Ciencias Médicas, Cuenca, Ecuador.

${ }^{3}$ Ministerio de Salud Pública, Baca Ortiz Hospital, Quito, Ecuador.

${ }^{4}$ Universidad de Cartagena, Facultad de Medicina, Grupo de Investigación UNIMOL, Cartagena de Indias, Colombia.

${ }^{5}$ Universidad Simón Bolívar, Facultad de Ciencias Básicas y Biomédicas, Barranquilla, Colombia.
}

Received October 07, 2020, and in revised form May 01, 2021. Accepted for publication May 24, 2021.

*Corresponding Author:

Juan Carlos Pozo Palacios, Email: juanc.pozop@ucuenca.edu.ec 
hyperplasia were unknown, thus were included in the NBS due that their early diagnosis and treatment prevent intellectual disabilities and newborn deaths [5].

The NBS in Ecuador is a centralized program. The collection is made around the country in MPH health centers and hospitals. The screening program collects blood samples by heel-prick up to 8 days after birth. Posteriorly, the samples are spotted on FTA cards and sent to an MPH institution called located in Quito, which is in charge of the NBS. From 2011 until 2016, the samples were analyzed by fluorometry in the institution through a collaboration agreement between Cuba and Ecuador [5]. From 2017 to this day, the MPH send the samples to an external laboratory, where the analysis is performed by timeresolved fluoroimmunoassay [8]. A study conducted in 2014 about fluorometry technology, described a test specificity of $95.7 \%$ and VPP of 0,63\% [9], and a research conducted in Colorado - United States about time-resolved fluoroimmunoassay in neonatal screening, described a specificity of $99 \%$ and VPP of $0,68 \%$ [10].

Phenylketonuria, galactosemia, and congenital adrenal hyperplasia have an autosomal recessive Mendelian inheritance pattern. Phenylketonuria is caused by a mutation in the gene encoding phenylalanine hydroxylase $(\mathrm{PAH})$, which catalyzes the hydroxylation of phenylalanine (Phe) generating tyrosine (Tyr) [11]. Galactosemia is caused by mutations of the genes encoding the Leloir pathway enzymes: galactokinase (GALK), galactose-1-phosphate uridyltransferase (GALT), and UDPgalactose 4 -epimerase (GALE) [12]. In $90 \%-95 \%$ of cases, Congenital Adrenal Hyperplasia is caused by a mutation in the CYP21A2 gene; other less frequent are caused due to 17-alphahydroxylase deficiency, 3-beta-hydroxysteroid dehydrogenase deficiency, 11-beta-hydroxylase deficiency, and cytochrome P450 oxidoreductase deficiency [13]. Alternatively, congenital hypothyroidism has a complex etiology that can be divided into primary, secondary, or peripheral etiologies ( $85 \%$ is caused by Thyroid dysgenesis) [14].

Even though screening for metabolic disorders has been available through public health care for some years in Ecuador, there are no studies on rates and distribution of NBS disorders in the country, neither in public health records or medical literature. Geospatial studies are wide use in epidemiological studies; their purpose is to use tools that help analyze the spatial variability of diseases and health determinants in a geographic area [15]. This study described the spatial distribution of individuals with an inborn metabolic disease by using data from the Newborn Screening Program in Ecuador between 2012 and 2019.

\section{Methods}

\section{Study area and population}

This is an ecological study that used distribution and spatial analysis. This study was conducted in Ecuador, a country multiethnic located on the west coast of the northern South
American continent and which is divided into four regions with different climate conditions: The Pacific Coast Line (the Coast), Highlands (Andes mountains), Amazonia (eastern region) and Galapagos Islands. At the same time, these four regions are divided into 24 provinces.

\section{Data collection}

Dataset was taken from the registry of the national NBS program of the Ecuadorian Health Ministry between January 2012 and December 2019. This registry contains all data of tested patients and the data of positive case surveillance. The population characteristics, demographic distribution by provinces, and geographic files were obtained from the website of the "Instituto Nacional de Estadísticas y Censos", which is the governing body of national statistics and responsible for generating official statistics of Ecuador.

\section{Data analysis}

We calculated the adjusted cumulative incidence of newborn screening disorders with the positive new cases during the study divided by the total of newborns with screening tests performed per 100000 in every province. The spatial analysis unit used to prepare thematic maps was the provinces. We performed a spatial distribution of the NBS disorders tested. The spatial analysis and map modeling were conducted in the program QGIS 3.12.

\section{Results}

A total of 2278189 children were born in Ecuador between January 2012 and December 2019, of which 74.64\% (1 700440 children) were screened and registered in the Newborn Screening Program Database. Of these, 393 cases (0.02\%) presented congenital disorders detected by the program. Congenital hypothyroidism was presented in most of the cases ( 270 cases, $68.70 \%$ ), followed by congenital adrenal hyperplasia ( 84 cases; $21.37 \%$ ), phenylketonuria (26 cases; $6.62 \%$ ), and galactosemia (13 cases; $3.31 \%$ ) (Figure 1 ).

Overall, female cases predominated (61,06\%), with a female/ male ratio of 1.57 (Table 1). In the case of phenylketonuria and congenital adrenal hyperplasia, the cases registered were slightly higher in males. By contrast, congenital hypothyroidism was higher in female patients. In Galactosemia's cases was equitable for both genders.

The incidence of newborn disease screening in Ecuador was 23.10 per 100000 newborns screened (95\% CI: 17.77 to 28.45). The congenital hypothyroidism incidence rate was 15.88 per 100000 neonates screened (95\% CI: 12.80 to 18.96 ), the congenital adrenal hyperplasia incidence rate was 4.94 per 100000 neonates screened (95\% CI: 2.47 to 7.41), the phenylketonuria incidence rate was 1.53 per 100000 neonates screened (95\% CI: 0.78 to 2.28) and galactosemia incidence was 0.76 per 100000 neonates screened (95\% CI: 0.37 to 1.16 ). 
Table 1. Cases by the Neonatal Screening Program classified by type of disorder and sex.

\begin{tabular}{|c|c|c|c|c|}
\hline \multirow{2}{*}{ NBS Disorder } & \multirow{2}{*}{ Number of cases } & \multicolumn{2}{|c|}{ SEX } & \multirow{2}{*}{ FEMALE - MALE RATIO } \\
\hline & & FEMALE & MALE & \\
\hline Phenylketonuria & 26 & 10 & 16 & 0.63 \\
\hline Galactosemia & 13 & 7 & 6 & 1.17 \\
\hline Congenital adrenal hyperplasia & 84 & 38 & 46 & 0.83 \\
\hline Congenital hypothyroidism & 270 & 185 & 85 & 2.18 \\
\hline Total & 393 & 240 & 153 & 1.57 \\
\hline
\end{tabular}

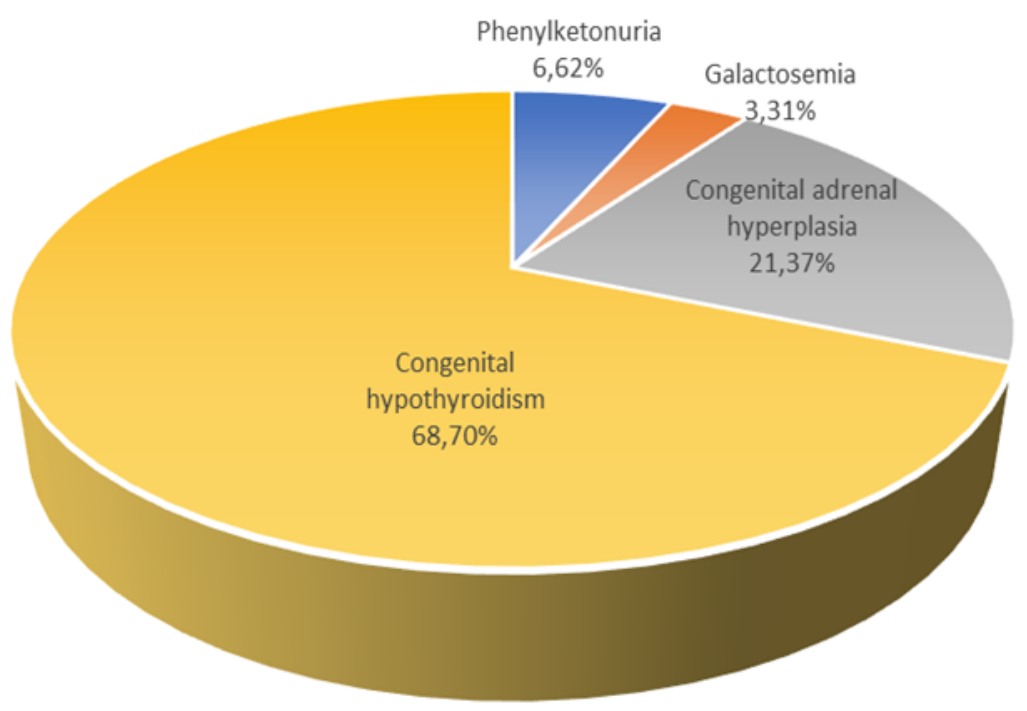

Figure 1. Cases diagnosed by the NBS Program between 2012 and 2019 in Ecuador.

Regarding the frequency by provinces, provinces with higher populations and births present a higher frequency of NBS cases. Guayas, Pichincha, and Manabí present a higher frequency of children with NBS-positive cases in phenylketonuria, galactosemia, and congenital hypothyroidism. Although, if we compare the congenital adrenal hyperplasia absolute frequency, it is higher in five provinces with lower births than Manabí (Azuay, Loja, Imbabura, Cañar, and Chimborazo).

During its first year of operation (2012), the NBS program detected 66 cases. In 2013, the year with the highest registration, cases detected increased to 80 , a marked increase in the cases of congenital hypothyroidism and adrenal hyperplasia were observed. The number of new cases registered each year decreased in 2015 and 2016. Posteriorly to these years, the program increased the frequency of detected cases (Figure 2).

Figure 3 shows that the eastern and southern provinces of Ecuador presented the highest newborn disease incidence in the country. In the eastern region, the provinces of Pastaza, Morona Santiago, and Sucumbios obtained a cumulative incidence larger than 30.5 per 100000 live births. In the Andes Mountains region, the highest incidence was in Loja, followed by the provinces of
Cotopaxi, Cañar, and Azuay. On the other hand, El Oro was the province with the highest incidence in the Pacific Coast Line. Among the 24 provinces, Morona Santiago and Pastaza got the main cumulative incidence rate (50.25 and 50.22 per 100000 neonates, respectively). There were no cases of NBS disorder in the Galapagos Islands.

Figure 4 shows that the incidence rate of the different disorders diagnosed by the NBS program varies between provinces. Phenylketonuria was registered in 11 provinces, being Cotopaxi, Andes Mountains, which presented the highest incidence rate. Only 7 provinces reported galactosemia, with the highest rate reported in Morona Santiago, Amazonia. On the other hand, 19 provinces reported positive cases of congenital adrenal hyperplasia, the highest incidence rate was registered in the province of Cañar. However, the provinces of Loja, Imbabura, Carchi, and Pastaza achieved significant rates compared to the rest of the provinces. Regarding congenital hypothyroidism, it was reported in 21/24 provinces (not presented in Zamora Chinchipe and Galapagos). The highest rates for this disease were found in Morona Santiago and Pastaza; both provinces of the Amazon region. 


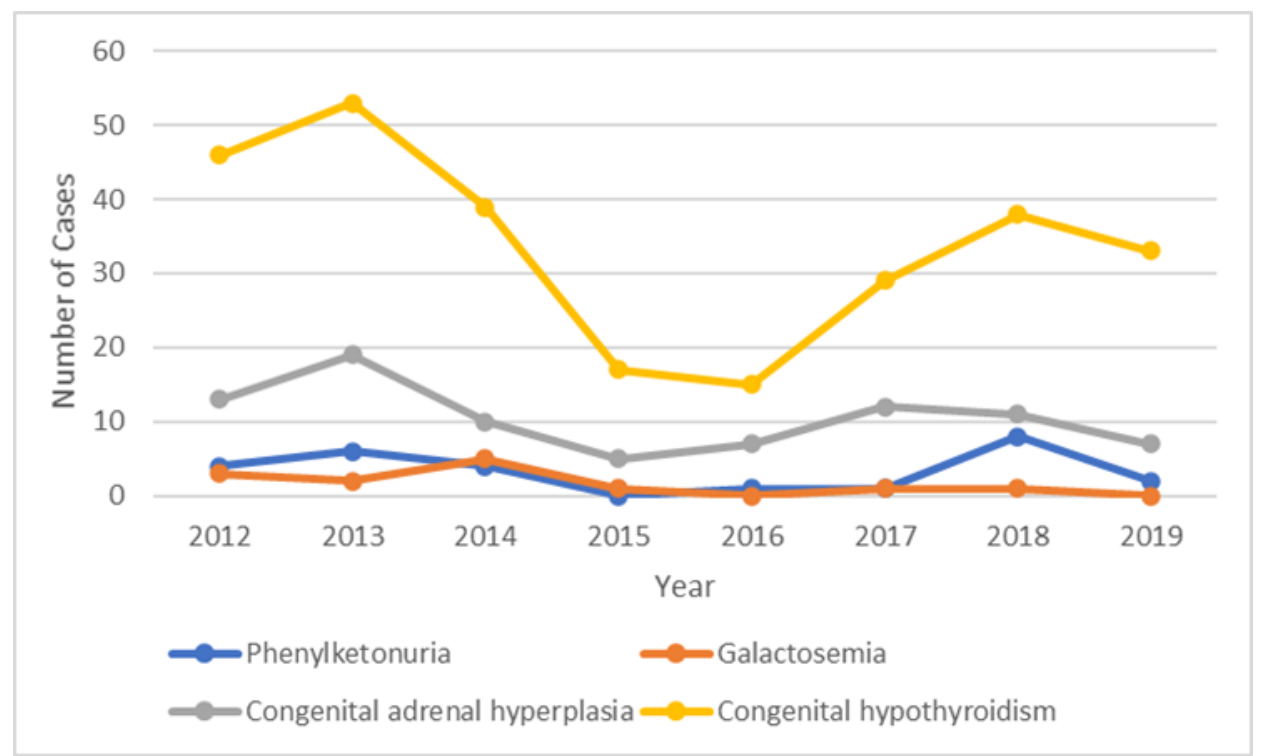

Figure 2. Cases diagnosed by the NBS Program distributed by years in Ecuador, 2012-2019.

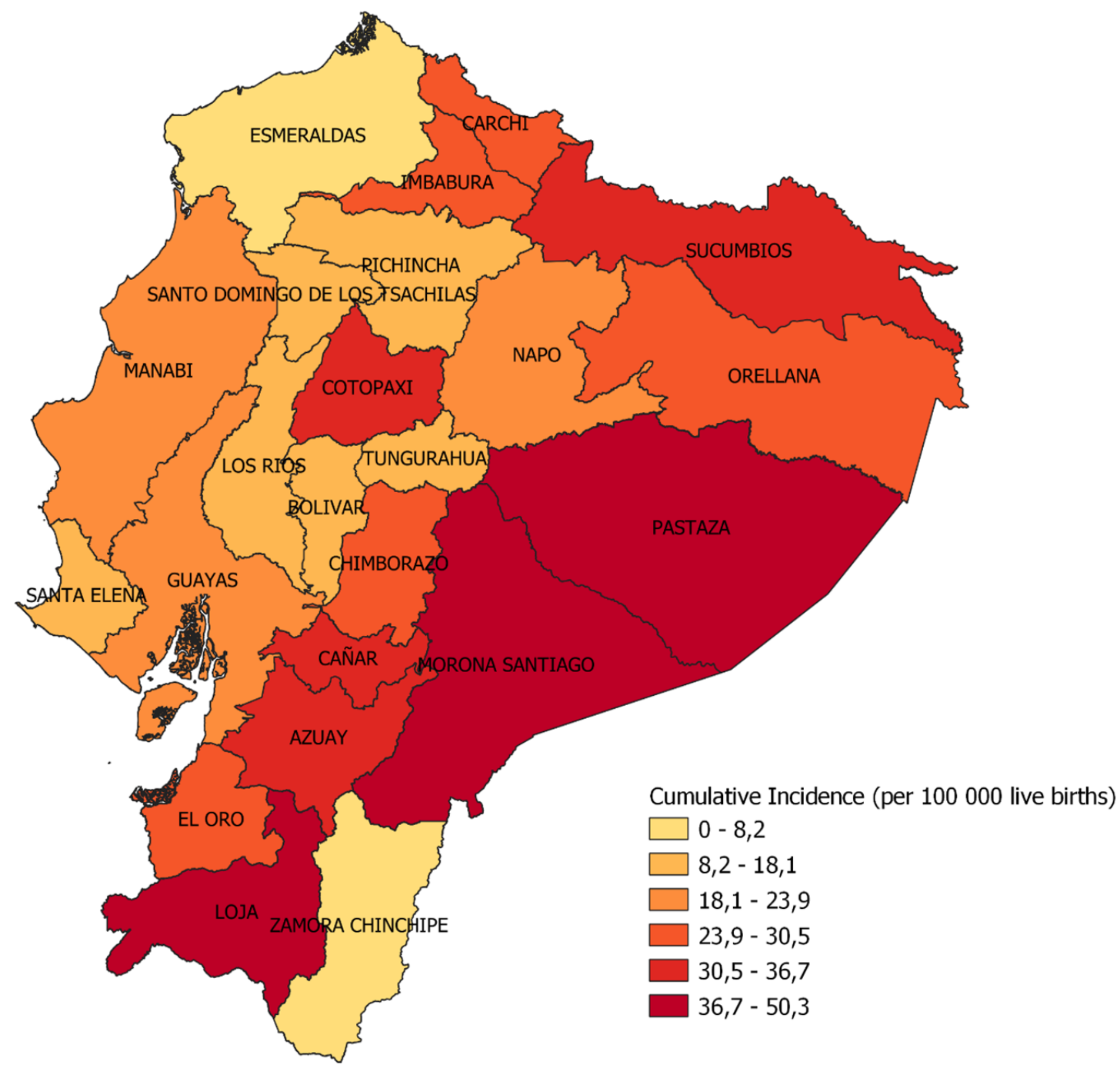

Figure 3. Spatial distribution of newborn screening disorders diagnosed in Ecuador, 2012 - 2019. 

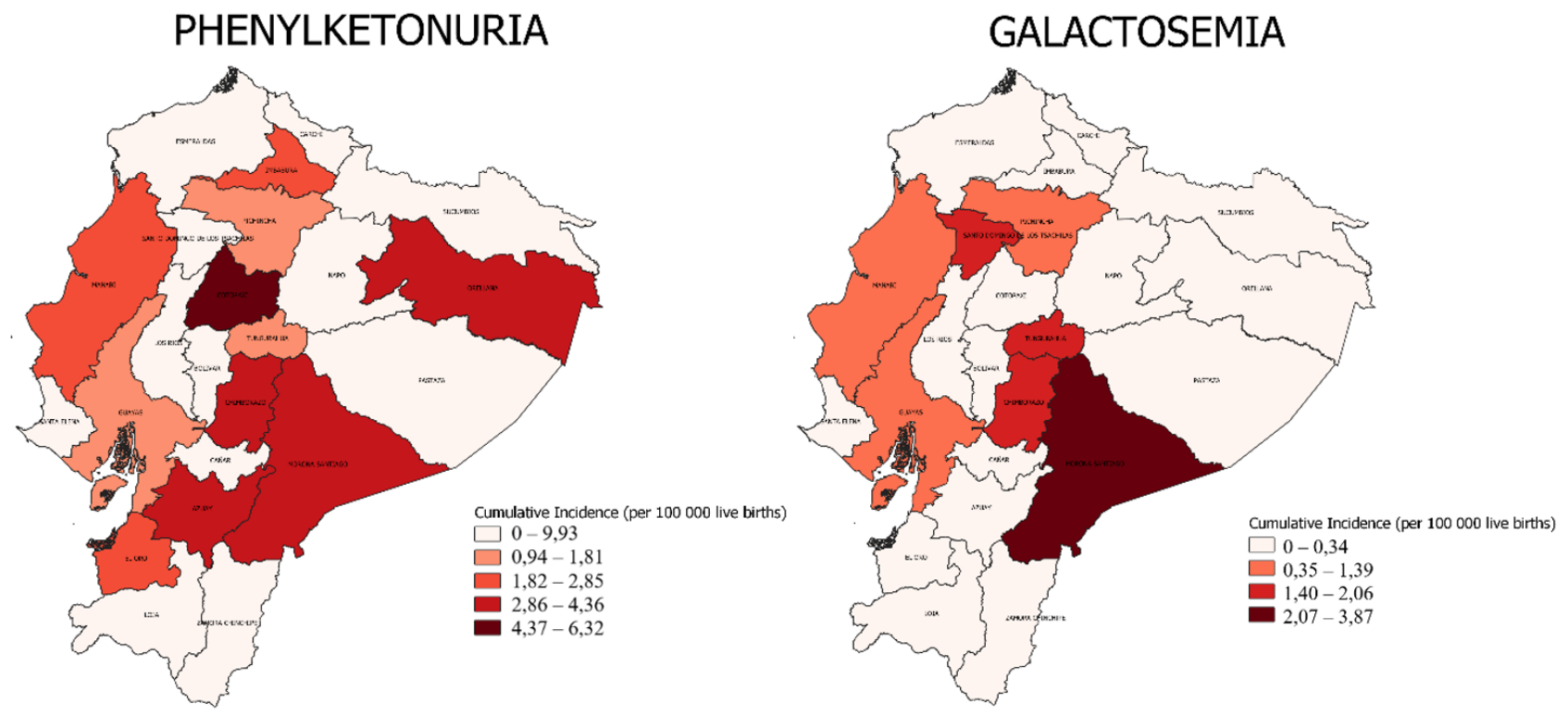

\section{CONGENITAL ADRENAL HYPERPLASIA}
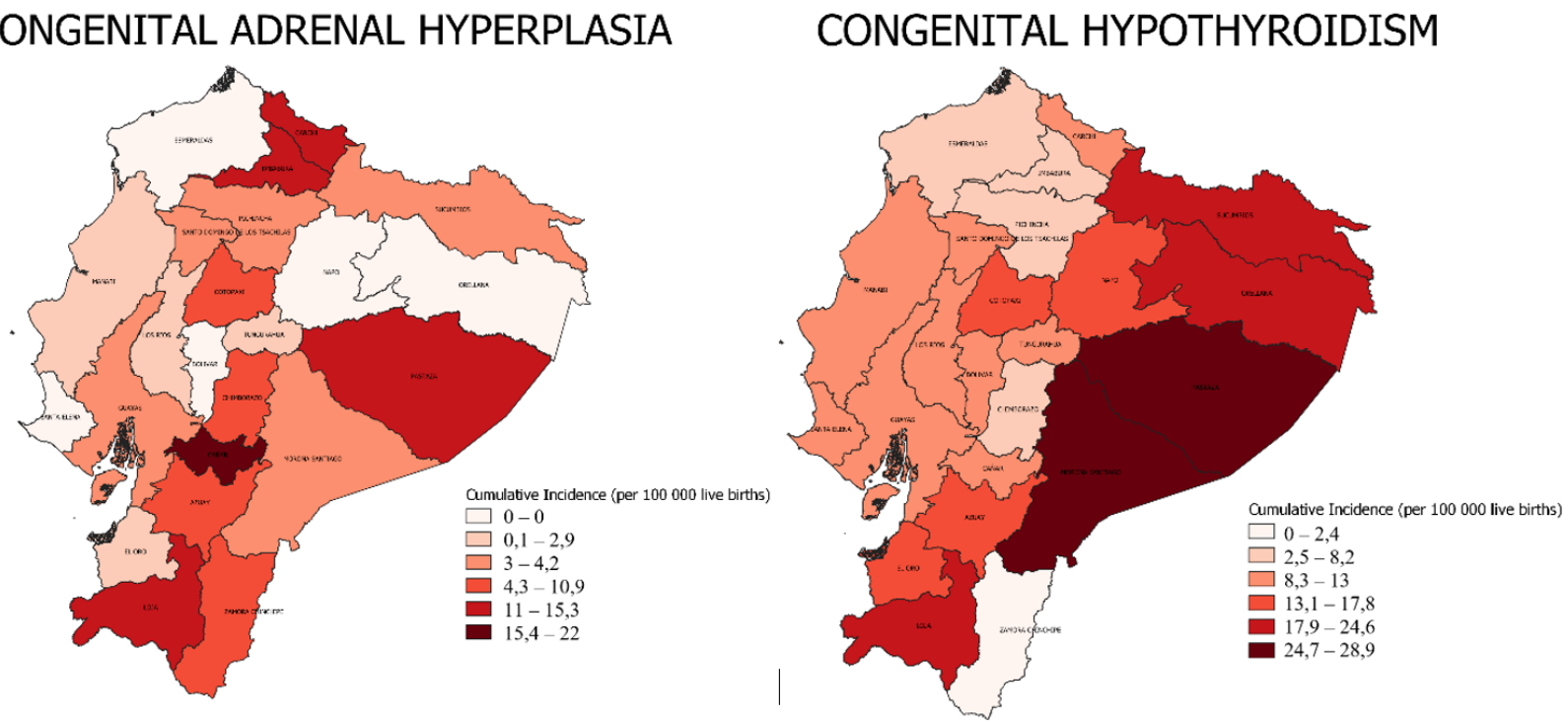

Figure 4. Spatial distribution of newborn screening disorders diagnosed in Ecuador by type disorder, 2012 - 2019.

\section{Discussion}

This study describes the rate and geographical distribution of the four metabolic disorders of the NBS program in Ecuador. We found that the incidence rate of phenylketonuria in Ecuador was lower than the world average described by Shoraka $(6.00$ per 100000 live births) [16]. Borrajo described an incidence in Latin America between 1.90 and 6.61 per 100000 live births [17]. Comparatively, the Ecuadorian cumulative rate in the last 8 years was slightly lower (1.53 per 100000 live births). On the other hand, we found relatively higher incidences in provinces such as in Cotopaxi, which obtained an incidence of 6.32 per 100000 live births, the highest rate in Ecuador. Galactosemia rate in Ecuador was almost half of the worldwide incidence (1.66 to 2.5 per 100000 live births) [18], however, in Morona Santiago the incidence rate was higher (3.86 per 100000 live births).
Congenital hypothyroidism occurs in $1 / 3000$ to $1 / 4000$ worldwide (25 - 33 cases per 100000 live births [19]. However, the average rate in Latin America reaches 36.01 per 100,000 live births [17]. In reference, a higher incidence of congenital hypothyroidism in the Hispanic population compared to other ethnic groups has been reported [20,21]. In this study, we found provinces such as Morona Santiago, Pastaza, and Loja with rates of 28.85, 26.77, and 24.62, respectively. These incidence rates were the highest in Ecuador, however, were lower than the Latin American average.

Congenital adrenal hyperplasia occurs in 6,67 to 7,69 per 100 000 live births around the world [22]. Overall, the Ecuadorian rate was lower. However, 9 provinces obtained higher rates than the world average: Cañar (22.03 per 100000 live births), Imbabura (15.31 per 100000 live births), Loja (14.43 per 100 000 live births), Pastaza (14.38 per 100000 live births), Carchi 
(12.62 per 100000 live births), Azuay (10.88 per 100000 live births), Chimborazo (10.27 per 100000 live births), Cotopaxi (8.43 per 100000 live births) and Zamora Chinchipe (8.23 per 100000 live births).

Phenylketonuria, galactosemia, and congenital adrenal hyperplasia frequencies should be similar in males and females due they are autosomal recessive disorders [23]. This is in line with what was observed in our cohort of cases of these disorders. In the case of congenital adrenal hyperplasia, it is known that a female-male ratio increases in places without an NBS program, this is due to unrecognized male deaths as a consequence of poor diagnosis and treatment [23]. In this study, a similar sex ratio of congenital adrenal hyperplasia with a slight predominance of male cases was observed, this could indicate a timely execution in the diagnosis of congenital adrenal hyperplasia by the NBS program in Ecuador. Regarding congenital hypothyroidism, female cases exceeded male cases by more than $100 \%$, this is similar to international rates that describe a higher incidence of the disease in women [21].

Three of the four diseases examined, except for congenital adrenal hyperplasia, are below the world average. These low rates need special attention because they could spell a deficiency in the program. It is important to compare the coverage of the program in different provinces to find the causes that make it difficult to achieve the planned coverage [24]. Another important part of the program involves knowing the different stages of the analysis: pre-analytical (collection, sending, and receiving of samples), analytical (analysis laboratory), and post-analytical (report of results, the initiation of the intervention, and confirmation of the diagnosis). All these stages require adequate time and quality control [25].

Currently, there is no description of false-negative cases in the national NBS program in Ecuador, however, there are differences in coverage, which is evidenced in the lack of case detection in some provinces. For example, if we compare the congenital hypothyroidism detected in the eastern provinces, Zamora Chinchipe detected a very low number of cases. This implies that the NBS program no the same quality in all the provinces. It is important to improve the epidemiological surveillance system that collects patients who are diagnosed outside of the neonatal metabolic screening and gather data of cases that escape the diagnosis of neonatal screening [26]. However, for subsequent studies, it is important to continually evaluate and search for the best diagnostic option and the best tools for improving program efficiency.

Variations in the frequency of cases of the same disease in regions different is an example of the complexity of its population and genetic diversity [27]. There are many factors related to the etiology of congenital hypothyroidism (multifactorial disorder). However, dietary iodine deficiency is the leading cause of congenital hypothyroidism around the world [28]. In Ecuador, Fierro et all, described in the year 1970 a high prevalence of cretinism in communities of the Andes due to iodine deficiency in the diet [29]. Although there is no information on the behavior of congenital hypothyroidism in the eastern provinces in the literature, we suggest that the possible cause of the high prevalence of congenital hypothyroidism is due to characteristics of the diet of these communities like goitrogenic food consumption and insufficient use of iodized salt in the diet [30].

Another possible explanation for a higher rate in some provinces than others is the genetic composition. Phenylketonuria, galactosemia, and congenital adrenal hyperplasia have an autosomal recessive inheritance pattern and occur with increased frequency in the offspring of consanguineous marriages [31], or populations where an original "founder mutation" occurs and is subsequently propagated throughout the population in future generations [32].

Ecuador is a country with a mixture of different ethnicities and cultures. Zambrano et al. published an ancestry analysis in the Ecuadorian population, this study explained the Ecuadorian genetic composition as a mixture of three ancestors: Native Americans, European and African descendants in a different proportion. Native American ancestry is the principal in all regions, more than $51 \%$. European and African ancestry were in a lower proportion and vary in different regions of the country (there is a major African genetic composition of the Coast compare in the Highlands and Amazonia [33]. Some communities could present a higher rate of specific NBS disorders in some provinces, while in other communities, the rates are low, it could be the product of ethnic and geographical differences in gene polymorphisms.

Consanguinity is also an important factor that increases the probability of inheritance of a recessive mutation in a homozygous state [31]. The prevalence rate of consanguinity in people with disabilities was 0.31 per 1000 people in Ecuador [34]. Lardoet et al. described that the provinces with were Loja and Cañar were the provinces with a higher rate of consanguinity in people with disabilities [7]. In this study, Cañar incidence rate of congenital adrenal hyperplasia tripled the world average rates and Loja incidence rate was more than double for the same disease. This extremely high rate could be the result of pathogenic polymorphisms, therefore, studies are needed to identify genetic risk factors in these populations. This information could help to identify some factors that generate a different distribution of the incidence rates of innate metabolic disorders and improve the NBS program in Ecuador.

\section{Conclusions}

Newborn screening disorder rates differ between types of disorder and provinces in Ecuador. In some provinces, the incidence rate is lower than the world average while in some cases the incidence is higher. We suggest that the lower rates are due to NBS program quality differences and the higher rates are primarily due to the impact of ethnicity and consanguinity in the country. This study provides recent epidemiological data of the NBS disorders in Ecuador; this information is useful to those providing and planning services for patients with an inherited metabolic disorder. 


\section{Acknowledgments}

The authors wish to thank all the Ecuadorian Newborn Screening Program for their support and their everyday effort in taking care of the children with inborn metabolism disorders.

\section{Funding}

This research received no specific grant from any funding agency in the public, commercial, or not-for-profit sectors.

\section{Declaration of conflict of interest}

The authors declare no conflict of interest.

\section{References}

1. Powell CM. What is Newborn Screening? N C Med J. 2019;80(1):32-36. doi:10.18043/ncm.80.1.32

2. Pitt JJ. Newborn Screening. Clin Biochem Rev. 2010;31(2):5768.

3. Jansen ME, Metternick-Jones SC, Lister KJ. International differences in the evaluation of conditions for newborn bloodspot screening: a review of scientific literature and policy documents. Eur J Hum Genet. 2016;25(1):10-16. doi:10.1038/ejhg.2016.126

4. Therrell BL, Padilla CD, Loeber JG, Kneisser I, Saadallah A, Borrajo GJC, Adams J. Current status of newborn screening worldwide: 2015. Semin Perinatol. 2015;39(3):171-187. doi:10.1053/j.semperi.2015.03.002

5. Ecuadorian Ministry of Public Health. Proyecto de Tamizaje Metabólico Neonatal. https://www.salud.gob. ec/proyecto-de-tamizaje-metabolico-neonatal/. Published 2014. Accessed September 3, 2020.

6. Vicepresidencia de la Republica del Ecuador. El Tamizaje aspira prevenir 251 casos de discapacidad intelectual al año. https://www.vicepresidencia.gob.ec/el-tamizaje-neonatalaspira-prevenir-251-casos-de-discapacidad-intelectual-alano/. Accessed December 23, 2020.

7. Ferrer RL, Puljals RR, Camacho A, Arguello MJ. Consanguinidad y agregación familiar en personas con discapacidad intelectual en la República del Ecuador. Rev Cub Gen. 2011;5(2-3):64-69.

8. Ecuadorian Ministry of Public Health. MSP y YACHAYNETLAB firman contrato para tamizaje metabólico neonatal. https://www.salud.gob.ec/msp-y-yachay-netlabfirman-contrato-para-tamizaje-metabolico-neonatal/. Published 2017. Accessed December 23, 2020.

9. Rubio ACO, Guerrero BEV. Evaluación del desempeño del programa nacional de tamizaje metabólico neonatal del Ministerio de Salud Pública del Ecuador en el período comprendido desde enero a noviembre del 2014. [Especialista en Pediatría]. Quito: Pontificia Universidad Católica del Ecuador, Facultad de Medicina; 2015.

10. Liste TR, Caeiro ÁLG. El cribado neonatal de la hiperplasia suprarrenal congénita: una revision sistemática. Endocrinol Nutr. 2007;54(4):216-224. doi:10.1016/S15750922(07)71435-3

11. Williams RA, Mamotte CDS, Burnett JR. Phenylketonuria: an inborn error of phenylalanine metabolism. Clin Biochem Rev. 2008;29(1):31-41.

12. Demirbas D, Coelho AI, Rubio-Gozalbo ME, Berry GT. Hereditary galactosemia. Metabolism. 2018;83:188-196. doi:10.1016/j.metabol.2018.01.025

13. Witchel SF. Congenital adrenal Hyperplasia. J Pediatr Adolesc Gynecol. 2017;30(5):520-534. doi:10.1016/j. jpag.2017.04.001

14. Cherella CE, Wassner AJ. Congenital hypothyroidism: insights into pathogenesis and treatment. Int J Pediatr Endocrinol. 2017;2017:11. doi:10.1186/s13633-017-0051-0

15. Valbuena-García A-M, Rodriguez-Villamizar L-A. Análisis espacial en epidemiología: revisión de métodos. Rev Uni Ind Santander Salud. 2018;50(4):358-365. doi:10.18273/ revsal.v50n4-2018009

16. Shoraka HR, Haghdoost AA, Baneshi MR, Bagherinezhad Z, Zolala F. Global prevalence of classic phenylketonuria based on Neonatal Screening Program Data: systematic review and meta-analysis. Clin Exp Pediatr. 2020;63(2):3443. doi:10.3345/kjp.2019.00465

17. Borrajo GJC. Newborn screening in Latin America at the beginning of the 21st century. J Inherit Metab Dis. 2007;30(4):466-481. doi:10.1007/s10545-007-0669-9

18. Pyhtila BM, Shaw KA, Neumann SE, Fridovich-Keil JL. Newborn screening for galactosemia in the United States: looking back, looking around, and looking ahead. JIMD Rep. 2014;15:79-93. doi:10.1007/8904_2014_302

19. Kopel J. A global perspective on newborn congenital hypothyroidism screening. Proc (Bayl Univ Med Cent). 2019;33(1):137-139. doi:10.1080/08998280.2019.1668715

20. Harris KB, Pass KA. Increase in congenital hypothyroidism in New York State and in the United States. Mol Genet Metab. 2007;91(3):268-277. doi:10.1016/j.ymgme.2007.03.012

21. Waller DK, Anderson JL, Lorey F, Cunningham GC. Risk factors for congenital hypothyroidism: an investigation of infant's birth weight, ethnicity, and gender in California, 1990-1998. Teratology. 2000;62(1):36-41. doi:10.1002/10969926(200007)62:1<36::aid-tera8>3.0.Co;2-w

22. New M, Yau M, Lekarev O, et al. Congenital Adrenal Hyperplasia. In: Feingold KR, Anawalt B, Boyce A, et al., eds. Endotext. South Dartmouth: MDText.com, Inc.; 2000. http://www.ncbi.nlm.nih.gov/books/nbk278953/. Accessed September 3, 2020. 
23. Nordenström A, Ahmed S, Jones J, et al. Female preponderance in Congenital Adrenal Hyperplasia due to CYP21 deficiency in England: implications for neonatal screening. Horm Res. 2005;63(1):22-28. doi:10.1159/000082896

24. Therrell Jr. BL, Padilla CD. Barriers to implementing sustainable national newborn screening in developing health systems. Int J Pediatr Adolesc Med. 2014;1(2):49-60. doi:10.1016/j.ijpam.2014.10.004

25. Sontag MK, Miller JI, McKasson S, et al. Newborn screening timeliness quality improvement initiative: impact of national recommendations and data repository. PLoS One. 2020;15(4):e0231050. doi:10.1371/journal.pone.0231050

26. Borrajo GJC. Newborn screening in Latin America: a brief overview of the state of the art. Am J Med Genet C Semin Med Genet. 2021. doi:10.1002/ajmg.c.31899

27. Vela-Amieva M, Belmont-Martínez L, Fernández-Lainez C, Ramirez-Frías C, Ibarra-González I. Frecuencia de enfermedades metabólicas congénitas susceptibles de ser identificadas por el tamiz neonatal. Acta Pediatr Mex. 2009;30(3):156-162.

28. Medda E, Olivieri A, Stazi MA, et al. Risk factors for congenital hypothyroidism: results of a population case-control study (1997-2003). Eur J Endocrinol. 2005;153(6):765-773. doi:10.1530/eje.1.02048
29. Fierro-Benitez R, Stanbury JB, Querido A, DeGroot L, Alban R, Cordova J. Endemic cretinism in the Andean region of Ecuador. J Clin Endocrinol Metab. 1970;30(2):228236. doi:10.1210/jcem-30-2-228

30. Leung AM, Pearce EN, Braverman LE. Iodine nutrition in pregnancy and lactation. Endocrinol Metab Clin North Am. 2011;40(4):765-777. doi:10.1016/j.ecl.2011.08.001

31. Keyfi F, Nasseri M, Nayerabadi S, Alaei A, Mokhtariye A, Varasteh A. Frequency of inborn errors of metabolism in a Northeastern Iranian sample with high consanguinity rates. Hum Hered. 2018;83(2):71-78. doi:10.1159/000488876

32. Chong JX, Ouwenga R, Anderson RL, Waggoner DJ, Ober C. A population-based study of autosomal-recessive diseasecausing mutations in a founder population. Am J Hum Genet. 2012;91(4):608-620. doi:10.1016/j.ajhg.2012.08.007

33. Zambrano AK, Gaviria A, Cobos-Navarrete S, et al. The three-hybrid genetic composition of an Ecuadorian population using AIMs-InDels compared with autosomes, mitochondrial DNA and Y chromosome data. Sci Rep. 2019;9(1):9247. doi:10.1038/s41598-019-45723-w

34. Paz-y-Mino C, López-Cortés A. Análisis de personas con discapacidad en población mestiza e indígena del Ecuador. VozAndes. 2015;26(1):7-18. 